\title{
Determination and evaluation of acid dissociation constants of some novel benzothiazole Schiff bases and their reduced analogs by spectroscopy
}

\author{
Cemil Öğretir*, Kamuran Görgün, Müjgan Özkütük, and Handan Can Sakarya \\ Department of Chemistry, Faculty of Sciences and Arts, Eskişehir Osmangazi University, 26480 \\ Eskişehir, Turkey \\ E-mail: cogretir@ogu.edu.tr
}

\begin{abstract}
The acid dissociation constants $\left(\mathrm{K}_{\mathrm{a}}\right)$ of eight novel biologically active benzothiazole Schiff bases were determined by UV-vis spectroscopic technique at $25 \pm 0.1{ }^{\circ} \mathrm{C}$. The calculated acidity constants, $\mathrm{pK}_{\mathrm{a}}$ values, were evaluated in structure elucidation and protonation - deprotonation mechanisms. The prototropic tautomerism was also studied.
\end{abstract}

Keywords: Benzothiazole Schiff bases, reduced analogs, acidity constant, tautomerism

\section{Introduction}

There has been a considerable interest in Schiff bases derived from salicylaldehyde because of their thermochromic and photochromic properties in the solid state. ${ }^{1-2}$ The biological activities of benzothiazole derivatives are well known. ${ }^{3-4}$ Much research has been devoted to study the metal ligand interaction and biological behavior of such derivatives which possess the azomethine $(\mathrm{CH}=\mathrm{N})$ linkage. ${ }^{5-6}$ The biological activity of these compounds may be connected to their ability to form complexes with certain metal ions which may lead to a "locked geometry" via the coordination mechanism so that only certain substances are able to become attached to the framework of this interaction. ${ }^{7-10}$ Many anticancer and antibacterial drugs are known to behave as versatile ligands, some of which exhibit increased anticancer activity when administered in the complex form with metal ions. ${ }^{11-13}$ It has been suggested that certain types of cancers are caused by viruses. The interaction between the metal ion and their ligands with cancer-associated viruses might represent an important route in designing, a new anticancer therapies for tumors that become resistant to the conventional drugs. ${ }^{14}$ A recent methodology to design novel antiviral therapies is achieved by coordinating a metal ion from an important bio-molecule, such as a zinc finger protein, with the antiviral agent, usually containing sulfur functionalities with good complex forming behavior. ${ }^{15}$ 
The acidity concept have been used in various areas of research, such as stereo-chemical and conformational structure determinations, the directions of nucleophilic and electrophilic attack, the stabilities of intermediates, the size of activation energies in organic reactions and the determination of the active sites of enzymes in biochemistry. ${ }^{16-19}$ Following our work on the synthesis of some novel benzothiazole Schiff bases we now are reporting on the acid dissociation constants of them to elucidate structure-reactivity relation-ships of these novel compounds. ${ }^{20}$

\section{Results and Discussions}

There are two series of molecules in this work. The first series consists of four compounds $\mathbf{1}-\mathbf{4}$ and they are all of them are novel Schiff bases. The second series contains the reduced forms of these novel Schiff bases and they are compound $\mathbf{5 - 8}$ (Table 1).

The first four compounds exhibit proton tautomerism. Therefore, we have concentrated on the proton tautomerism and intramolecular H-bond forming of compounds 1-4. These two phenomena can have pronounced effect on acid-base behaviours as well as structural properties of organic molecules.

\section{Tautomerism and H-bonding}

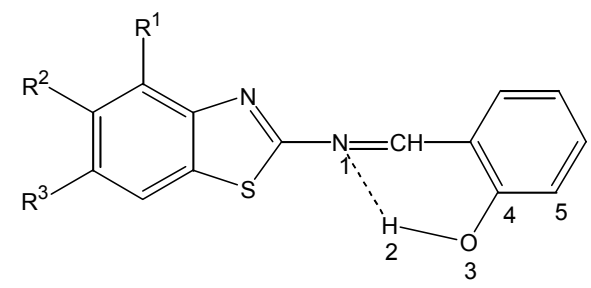

Scheme 1. H-bonding possibility in compounds $\mathbf{1}-\mathbf{4}$.

The formation of $\mathrm{B}$ and $\mathrm{C}$ in acidic or basic media seems to be very unlikely due to loss of aromatic property of the phenol ring (Scheme 2).

\section{Acidity constants}

Considering the structures of the Schiff bases 1-4 we can deduce that they have two protonation sites the first one is the aza-nitrogen atom of the benzothiazole ring and imino- nitrogen atom which is substituted at $2 \mathrm{C}$ position of the benzothiazole ring. These compounds, however, possess one deprotonation site (i.e. OH group of the phenol ring) and they are in enol-imino form (Scheme 2). On the other hand when they are in keto-imino tautomeric form (B) they have two protonation sites (i.e. imino nitrogen atom and ketonic oxygen atom of the phenol ring) and one deprotonation site (i.e. -NH- group of the benzothiazole ring). However, when they are in ketoamine form (C), they have three protonation sites (i.e. aza nitrogen atom $=\mathrm{NH}$ of benzothiazole 
ring, amine group $-\mathrm{NH}$ - which is substituted at $2 \mathrm{C}$ position of benzothiazole ring and ketonic oxygen atom $=\mathrm{O}$ of the phenol ring) and they possess one deprotonation site (i.e. $-\mathrm{NH}$-group which is located at $2 \mathrm{C}$ position of the benzothiazole ring) (Scheme 2).
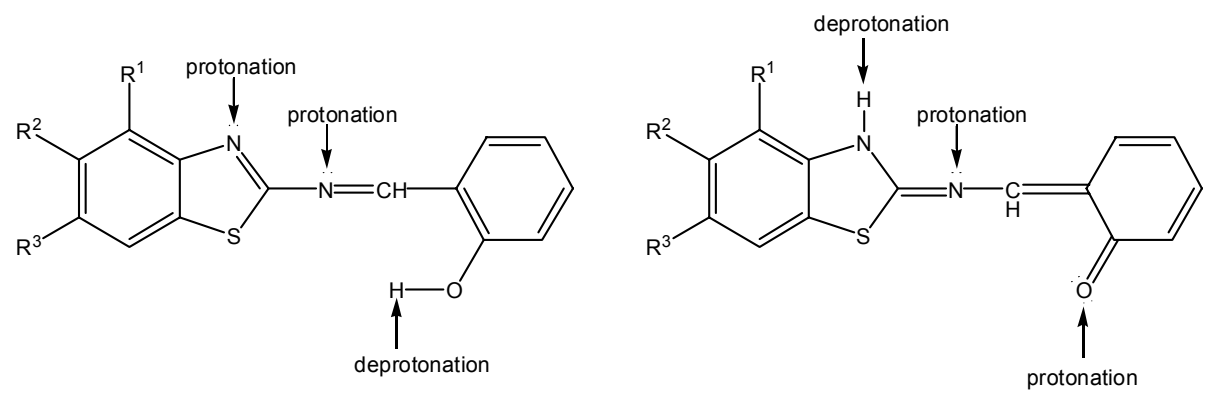

enol-imino form $(\mathrm{A})$

keto-imino form (B)

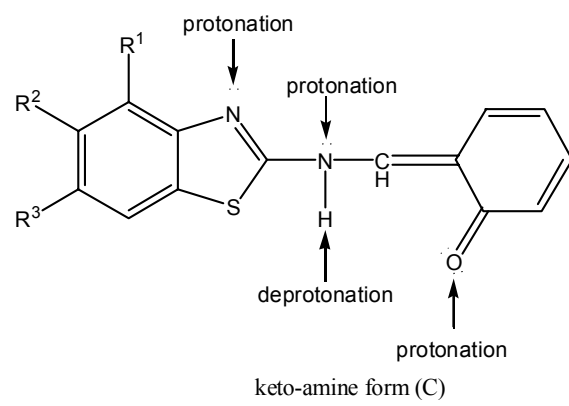

Scheme 2. Possible tautomeric forms of Schiff bases 1-4 via proton migration.

\section{Deprotonation (pK $\mathrm{K}_{\mathrm{a} 1}$ values)}

When we arrange the studied Schiff bases and their reduced derivatives in an increasing acidity order for deprotonation process we get the following sequence;

\begin{tabular}{lccccccccc} 
Molecule: & 8 & 5 & 6 & 7 & phenol & 1 & 3 & 2 & 4 \\
Half protonation $\left(\mathrm{H}^{1 / 2}\right)$ & 12.45 & 12.43 & 12.26 & 11.36 & 10.00 & 9.78 & 9.44 & 8.40 & 8.37 \\
& \multicolumn{1}{c}{ increasing acidity }
\end{tabular}

If we take the ionization constant of phenol (i.e. $\mathrm{pK}_{\mathrm{a}}=10$ ) as reference, we can say that the big groups (i.e. $\mathbf{S}$ and $\mathbf{R}$ ) act as ortho substituent on the ionization of Schiff bases and their reduced derivatives (Scheme 4 and 7) respectively. It seems that in molecules $\mathbf{1}-\mathbf{4}$ both the benzothiazole ring and phenol ring are on the same plane and the through conjugation lead to proton transfer from $\mathrm{OH}$ group to $\mathrm{N}$ atom of imino group, forming the zwitter ion iminium form (B), followed by a subsequent rearrangement into the keto-amine form (C). Under these conditions, the deprotonation may occur from $\mathrm{NH}$ group and rearrangement of anion (D) leads to anion (E). This means that deprotonation mechanism of these four molecule $\mathbf{1}-\mathbf{4}$ is different from the other molecules $\mathbf{5}-\mathbf{8}$ (Scheme 3 and Table 2). 


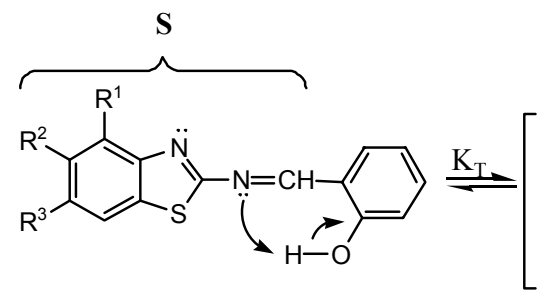

A

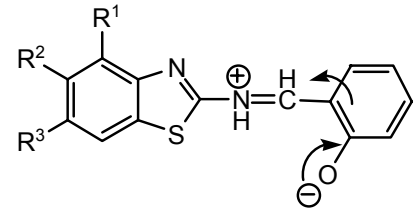

B

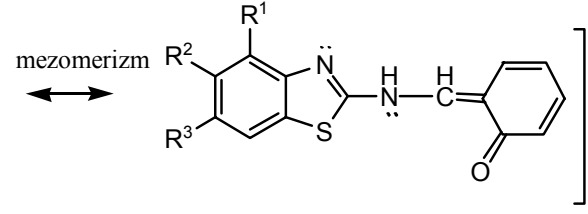

C

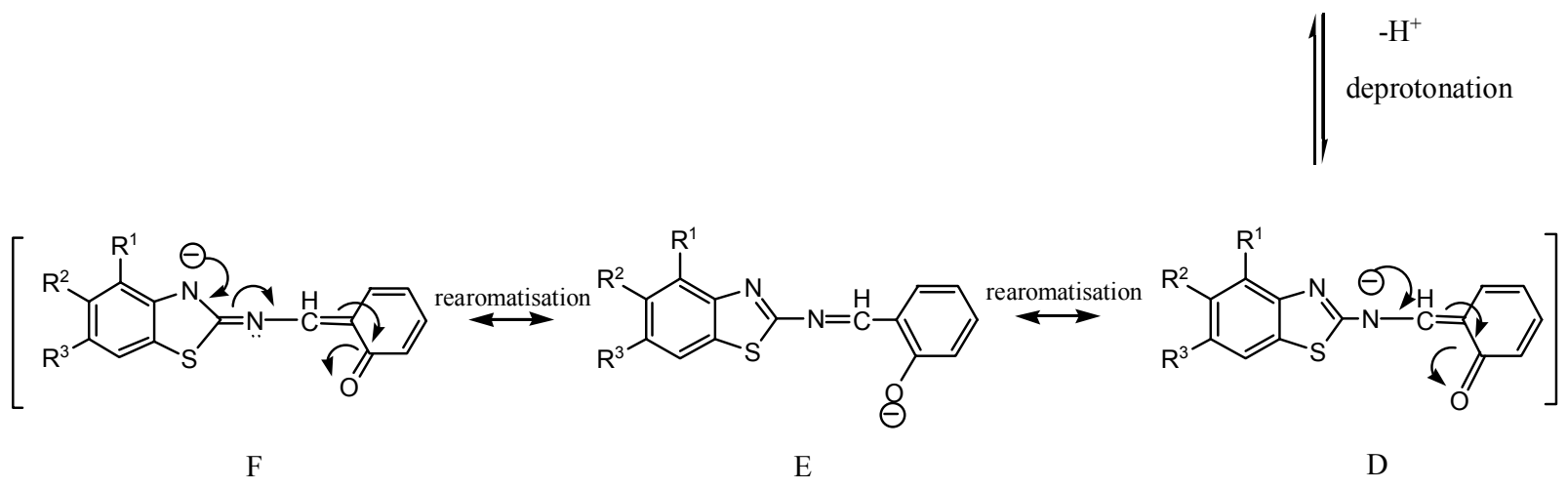

Scheme 3. Possible deprotonation patterns for molecules $1-4$.

In molecule $\mathbf{4}$, the two methyl groups at 5 and $\mathbf{6}$ position of benzothiazole ring make $\mathbf{S}$ group more electron-donating than the other molecules of 1-3 and keeping the proton more firmly make the molecule 4 more acidic (less basic) among the others. In molecule 1, however, there is no methyl group on benzothiazole ring and the $\mathbf{S}$ group becomes less electron-donating and consequently molecule $\mathbf{1}$ becomes less acidic (more basic).

In molecules $\mathbf{5}-\mathbf{8}$, there is no possibility of thorough conjugation. Therefore formation of keto forms are not feasible and presumably the deprotonation occurs at phenolic $\mathrm{OH}$ group. In here also dimethyl groups in molecule $\mathbf{8}$ were effective by making the $\mathbf{R}$ group more electron withdrawing but in opposite direction of molecule $\mathbf{4}$ as expected. Since there is no thorough conjunction, the only effect of group $\mathbf{R}$ is inductive electron donation and making the whole molecule more basic or less acidic. If we think the position of methyl group in molecule $\mathbf{7}$, the unusual effect of the $\mathbf{R}$ group can be expected (Scheme 3).

\section{First protonation ( $\mathrm{pK}_{\mathrm{a} 2}$ values)}

When we arrange the molecules with increasing acidity power for the first protonation, we get the following order:

\begin{tabular}{lllllllll} 
Molecule: & $\mathbf{1}$ & $\mathbf{4}$ & $\mathbf{5}$ & $\mathbf{3}$ & $\mathbf{2}$ & $\mathbf{8}$ & $\mathbf{7}$ & $\mathbf{6}$ \\
Half protonation $\left(\mathrm{H}^{1 / 2}\right)$ & 4.57 & 4.45 & 3.94 & 3.84 & 3.80 & 3.65 & 3.50 & 3.02 \\
\cline { 3 - 6 } & & & \multicolumn{5}{c}{ increasing acidity }
\end{tabular}


If we compare the obtained half protonation values of the studied molecules (Table 3) with the literature $\mathrm{pK}_{\mathrm{a}}$ values of 1.84 and 4.51 for the aza nitrogen atom protonation of benzothiazole ring $^{22,23}$ and 2-aminobenzothiazole ${ }^{24}$ molecules respectively, due to similarity of the obtained $\mathrm{pK}_{\mathrm{a}}$ values of this study we can conclude that the studied molecules were protonated with the same mechanism of these two molecules and that is the aza nitrogen atom protonation of the benzothiazole ring. The reduced derivatives of the corresponding Schiff bases are less basic (i.e. $\mathrm{pK}_{\mathrm{a}(5,6,7,8)}<\mathrm{pK}_{\mathrm{a}(1,2,3,4)} 5<1 ; 6<2 ; 7<3$ and $\left.8<4\right)$. This is an expected result because there are a through conjugation between the two rings namely benzothiazole and phenol ring in Schiff bases $\mathbf{1 - 4}$ which don't exist in their reduced derivatives 5 - 8 (Scheme 4).

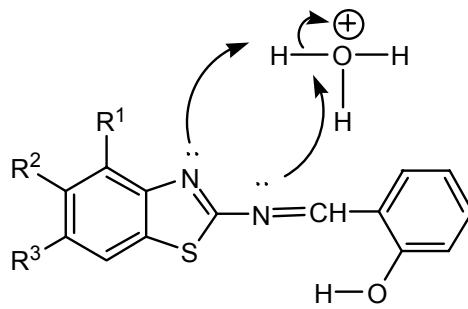

$+\mathrm{H}^{+} \| \mathrm{K}_{\mathrm{a}}$

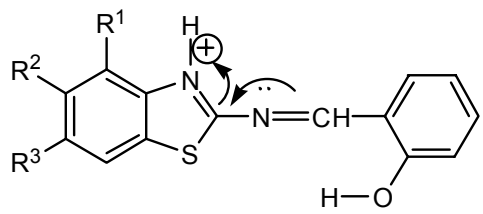<smiles>[Tl]C1CCCCC1</smiles><smiles>[R]c1cc2s/c(=N\c3ccccc3O)[nH]c2c([R])c1[R]</smiles>

enol-imino

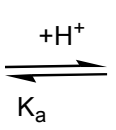

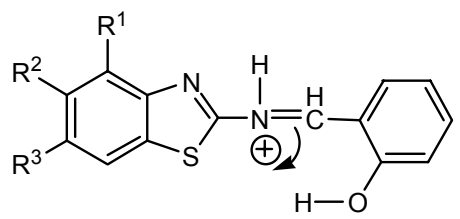

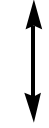<smiles>[R]c1cc2sc(N[CH]c3ccccc3O)nc2c([R])c1[R]</smiles>

eno-amine

Scheme 4. Possible first protonation patterns for molecules $\mathbf{1 - 4}$.

\section{Second protonation ( $\mathrm{pK}_{\mathrm{a} 3}$ values)}

When we are arrange the studied molecules with increasing acidity power for the second protonation, we get the following order:

Molecule:

$\begin{array}{llll}\mathbf{4} & \mathbf{2} & \mathbf{3} & \mathbf{1} \\ 3.10 & 2.18 & 1.86 & 1.30\end{array}$

Half protonation $\left(\mathrm{H}^{1 / 2}\right)$

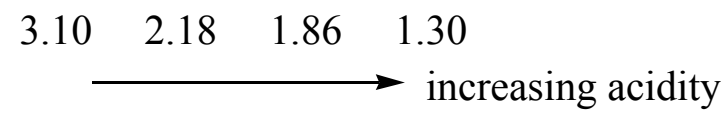


The half protonation values of 1.86 and 1.30 for compounds $\mathbf{3}$ and $\mathbf{1}$ are comparable with benzothiazole aza nitrogen atom protonation (i.e.1.84). So obviously the protonation had taken place at aza nitrogen atom of benzothiazole ring of these two compounds. Obviously strong electron - withdrawing effect of protonated imine group makes the ring nitrogen electron deficient. This means that molecules become more acidic. Following the second protonation, a subsequent mezomerization seems to occur to form a more stable carbonium ion (Scheme 5).

By considering the $\mathrm{pK}_{\mathrm{a}}$ value of 3.10 for molecule 4 which is quite different from the other three molecules $\mathbf{1}-\mathbf{3}$ which contains one methyl or no methyl group, we can predict that this bigger $\mathrm{pK}_{\mathrm{a}}$ value of this compound is expected because of inductively electron donating effect of dimethyl groups on benzothiazole ring.
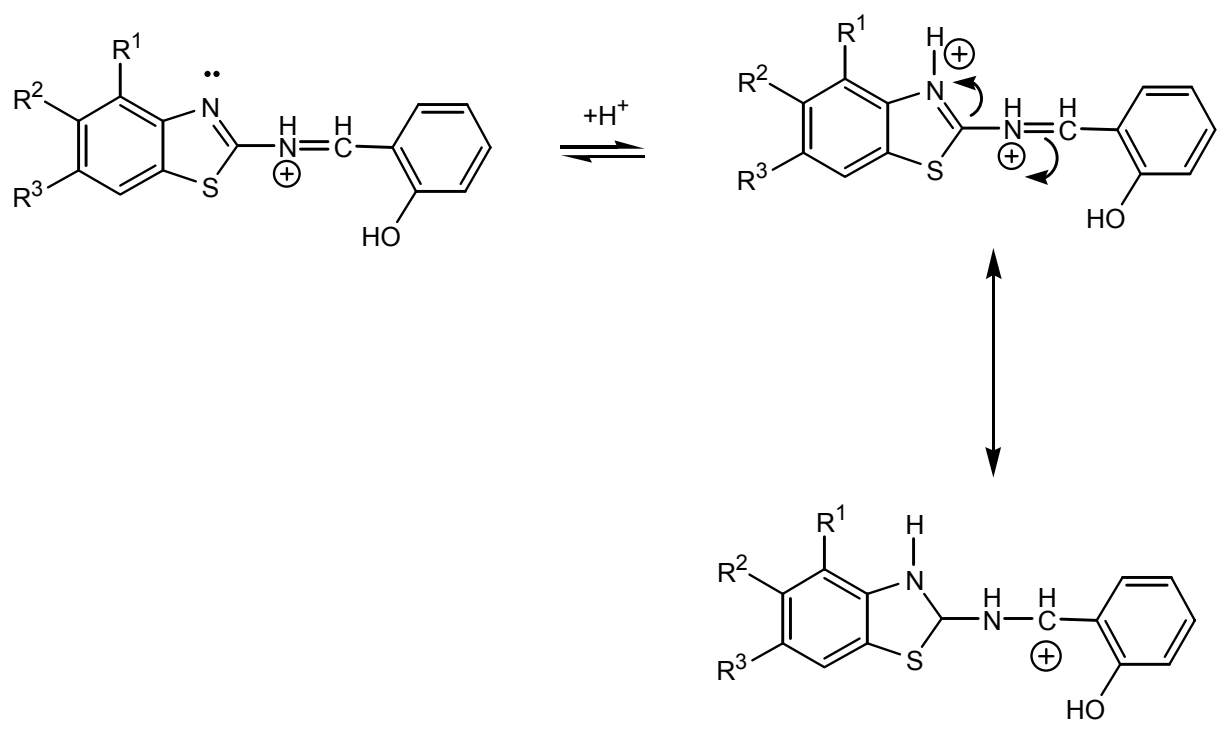

Scheme 5. Possible second protonation patterns for molecules $\mathbf{1}$ and $\mathbf{3 .}$

\section{Experimental Section}

General Procedures. The studied compounds (Table 1) were synthesized and the procedures of synthesis are described elsewhere. ${ }^{20}$ Methanol, ethanol, glycine, $\mathrm{KOH}, \mathrm{H}_{2} \mathrm{SO}_{4}, \mathrm{HCl}, \mathrm{CH}_{3} \mathrm{COOH}$, $\mathrm{CH}_{3} \mathrm{COONa}, \mathrm{NaOH}, \mathrm{KH}_{2} \mathrm{PO}_{4}, \mathrm{Na}_{2} \mathrm{CO}_{3}, \mathrm{NaHCO}_{3}$, phenolphthalein indicator, and standard buffer solutions were from Aldrich and were not purified further.

Apparatus. $\mathrm{pH}$ measurements were performed using a glass electrode. $\mathrm{pH}$ values of the standard buffer solutions were 1, 7, and 14 they were used in the calibration of the Orion $\mathrm{pH} /$ ion analyzer. The Ohaus Advanturer balance; a Scimadzu UV2450 PC UV-vis scanning spectrometer was used for measurements. 
Table 1. Nomenclature and formulae of the studied molecules [1-8]
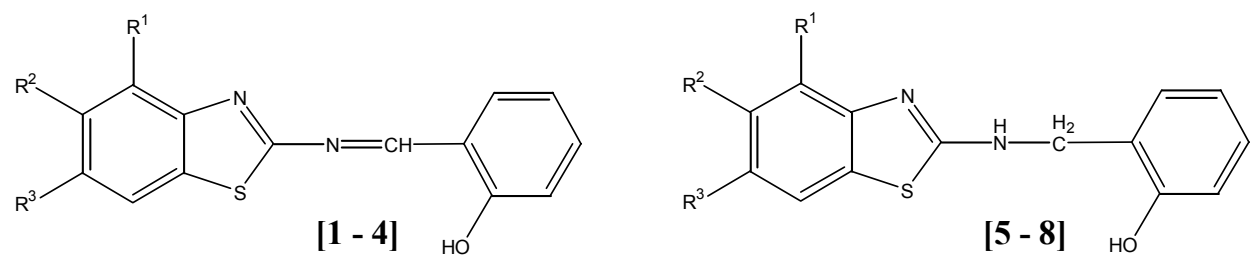

\begin{tabular}{clccc} 
Molecule & \multicolumn{1}{c}{ IUPAC Name } & $\mathrm{R}^{1}$ & $\mathrm{R}^{2}$ & $\mathrm{R}^{3}$ \\
\hline $\mathbf{1}$ & 2-(2-aza-2-benzothiazol-2-ylvinyl)phenol & $\mathrm{H}$ & $\mathrm{H}$ & $\mathrm{H}$ \\
$\mathbf{2}$ & 2-[2-aza-2-(4-methylbenzothiazol-2-yl)vinyl]phenol & $\mathrm{CH}_{3}$ & $\mathrm{H}$ & $\mathrm{H}$ \\
$\mathbf{3}$ & 2-[2-aza-2-(6-methylbenzothiazol-2-yl)vinyl]phenol & $\mathrm{H}$ & $\mathrm{H}$ & $\mathrm{CH}_{3}$ \\
$\mathbf{4}$ & 2-[2-aza-2-(5,6-dimethylbenzothiazol-2-yl)vinyl]phenol & $\mathrm{H}$ & $\mathrm{CH}_{3}$ & $\mathrm{CH}_{3}$ \\
$\mathbf{5}$ & 2-[(benzothiazol-2-ylamino)methyl]phenol & $\mathrm{H}$ & $\mathrm{H}$ & $\mathrm{H}$ \\
$\mathbf{6}$ & 2-\{[(4-methylbenzothiazol-2-yl)amino]methyl\}phenol & $\mathrm{CH}_{3}$ & $\mathrm{H}$ & $\mathrm{H}$ \\
$\mathbf{7}$ & 2-\{[(6-methylbenzothiazol-2-yl)amino]methyl\}phenol & $\mathrm{H}$ & $\mathrm{H}$ & $\mathrm{CH}_{3}$ \\
$\mathbf{8}$ & 2-\{[(5,6-dimethylbenzothiazol-2-yl)amino]methyl\}phenol & $\mathrm{H}$ & $\mathrm{CH}_{3}$ & $\mathrm{CH}_{3}$ \\
\hline
\end{tabular}

Procedure. Acid solutions were prepared with $\mathrm{H}_{2} \mathrm{SO}_{4}(\mathrm{w} / \mathrm{w})\left(0.0049\right.$ to $\left.96 \% \mathrm{H}_{2} \mathrm{SO}_{4}\right)$ in water. ${ }^{21}$ The $\mathrm{CO}_{2}$-free $\mathrm{NaOH}$ solutions were prepared with $\mathrm{NaOH}$ pellets $\left(1\right.$ to 16.4 mol.dm $\left.^{-3}\right)$ in water. ${ }^{25}$ Buffer solutions were prepared with procedures well described by using Perrin's desciription. ${ }^{26}$ Spectrometry is an ideal method ${ }^{27}$ when a substance is not soluble enough for potentiometry or when its $\mathrm{pK}_{\mathrm{a}}$ value is particularly low or high (e.g., less than 2 or more than 11).

The protonation of a weak base can be defined as follows: ${ }^{21}$

$$
\mathrm{HX}+\mathrm{SH} \rightleftharpoons \mathrm{X}^{-}+\mathrm{SH}_{2}^{+}
$$

where $\mathrm{SH}$ is the solvent, then the equilibrium constant might be expressed in terms of concentration and activity coefficient:

$$
K_{a}=\frac{a_{X}{ }^{-} a_{S H_{2}}{ }^{+}}{a_{H X}}
$$

where $a=\mathrm{c} \gamma ; a=$ activity constant; $\gamma=$ activity coefficient; $c=$ concentration:

$$
K_{a}=\frac{\left[X^{-}\right]}{H X} \frac{\gamma_{X}}{\gamma_{H X}} a_{S H_{2}{ }^{+}}=H_{x} \frac{\left[X^{-}\right]}{[H X]}
$$

Therefore, the Eq. 2 can be rearranged as follows:

$$
H_{x}=-\log h_{x}=p K_{a}-\log \frac{[H X]}{\left[H^{+}\right]}
$$


where $H_{\mathrm{x}}$ is an acidity function. The $\mathrm{H}_{\mathrm{o}}$ scale is defined such that, for the uncharged primary aniline indicators used, the plot of $\log I$ (i.e., $\log \left(\left[\mathrm{BH}^{+}\right] /[\mathrm{B}]\right)$ ) against $\mathrm{H}_{0}$ has unit slope. It was observed from work on bases other than the Hammett type that the slopes of the plots of $\log I$ against $\mathrm{H}_{\mathrm{o}}$, donated by $m$, were not always unity. Thus, series of structurally similar bases, like triarylmethanols ${ }^{28}$, primary amides ${ }^{29,30}$ and tertiary aromatic amines ${ }^{31}$ defined individual acidity functions $\left(\mathrm{H}_{\mathrm{R}}, \mathrm{H}_{\mathrm{A}}\right.$, and $\left.\mathrm{H}_{-}\right)$, which have a linear relationship to $\mathrm{H}_{\mathrm{o}}$ with $m$ values of 2.0, 0.6, and 1.3 , respectively. Yates proposed that any acidity function $\mathrm{H}_{\mathrm{x}}$ would be proportional to $\mathrm{H}_{\mathrm{o}}$ over the entire acidity range, that is, $\mathrm{H}_{\mathrm{x}}=\mathrm{mH}_{\mathrm{o}}$, with a common point $\mathrm{H}_{\mathrm{o}}=0 .{ }^{32}$

As explained in the previous paragraph plot of $\log I$ against $\mathrm{H}_{\mathrm{o}}$ does not yield the $\mathrm{pK}_{\mathrm{a}}$ at $\log$ $I=0$, unless it is an Hammett base, but yields the $H_{0}$ at half-protonation value $\left(H_{\mathrm{o}}{ }^{1 / 2}\right)$. The general Eq. 3 may therefore be applied and Eq. 4 can be obtained.

$$
\log I=m\left(H_{o}^{1 / 2}-H_{o}\right)
$$

By rearranging Eq.4 we obtain the following expression;

$$
\begin{gathered}
\log I=m H_{o}^{1 / 2}-m H_{o} \\
\log I=-m H_{o}^{1 / 2}+p K_{a} \text { and for } \log I=0
\end{gathered}
$$

rearranging the last expression we will produce Eq. 5:

$$
p K_{a}=m H_{o}^{1 / 2}
$$

Where $\mathrm{H}^{1 / 2}$ describes the half protonation value.

The general procedure applied as follows: a stock solution of the compound under investigation was prepared by dissolving the compound (about 10 to $20 \mathrm{mg}$ ) in water or sulfuric acid of known strength $(25 \mathrm{~mL})$ in a volumetric flask. Aliquots $(1 \mathrm{~mL})$ of this solution were transferred into $10 \mathrm{~mL}$ volumetric flask and diluted to the mark with sulfuric acid solutions of various strengths or buffers of various $\mathrm{pH}$. The total mass of solution in each flask was measured, and the mass percent of sulfuric acid in each solution was than calculated knowing the mass of sulfuric acid added and the total mass of the final solution. In the case of buffer solutions, the $\mathrm{pH}$ was measured before and after addition of the new solution. The optical density of each solution was then measured in $1 \mathrm{~cm}$ cells, against solvent blanks, using a constant temperature cell-holder Scimadzu UV2450 PC UV-Vis. A scanning spectrometer was thermostated at $25^{\circ} \mathrm{C}$ (to within $\pm 0.1^{\circ} \mathrm{C}$ ). The wavelengths were chosen such that the fully protonated form of the substrate had a much greater or a much smaller extinction coefficient than the neutral form. The analytical wavelengths, the half-protonation values, and the UV absorption maxima for each substrate were depicted in Tables 2 and 4.

Calculations of half-protonation values were carried out as follows; the sigmoid curve of optical density or extinction coefficients at the analytical wavelength $(\mathrm{OD}, \lambda)$ was first obtained (Figure 1). The optical density of the fully protonated molecule $\left(\mathrm{OD}_{\mathrm{ca}}\right.$, optical density of conjugated acid) and the pure free base $\left(\mathrm{OD}_{\mathrm{fb}}\right.$, optical density of free base) at an acidity were then calculated by linear extrapolation of the arms of the curve. Eq. 6 provides the ionization ratio where the $\mathrm{OD}_{\mathrm{obs}}$ (the observed optical density) was in turn converted into molar extinction $\epsilon_{\text {obs }}$ using Beers law of $\mathrm{OD}=\in b c\left(b=\right.$ cell width, $\mathrm{cm} ; c=$ concentration, mol.dm $\left.{ }^{-3}\right)$ : 


$$
I=\frac{\left[B H^{+}\right]}{[B]}=\frac{\left(O D_{o b s}-O D_{f b}\right)}{\left(O D_{c a}-O D_{o b s}\right)}=\frac{\left(\epsilon_{o b s}-\epsilon_{f b}\right)}{\left(\epsilon_{c a}-\epsilon_{o b s}\right)}
$$

The linear plot of $\log I$ against $\mathrm{Hx}$ or $\mathrm{pH}$, using the values $-1.0<\log I<1.0$, had slope $\mathrm{m}$, yielding half-protonation value as $H_{\mathrm{x}}^{1 / 2}$ or $\mathrm{pH}^{1 / 2}$ at $\log I=0$ The $p \mathrm{~K}_{\mathrm{a}}$ values were calculated by using Eq. 7 (Figure 2).

$$
p K_{a}=m H_{x}^{1 / 2}\left(\text { or } \mathrm{pH}^{1 / 2}\right)
$$

Table 2. The UV Spectral data and the acidity constants, $\mathrm{pK}_{\mathrm{a} 1}$ values, of compounds 1-8 for deprotonation process

\begin{tabular}{cccccc}
\hline & \multicolumn{2}{c}{ spectral maximum $\lambda / \mathrm{nm}$} & \multicolumn{3}{c}{ acidity measurements } \\
\cline { 2 - 6 } compound & $\begin{array}{c}\text { neutral }^{\mathrm{a}} \text { species } \\
\left(\log \in_{\max }\right)\end{array}$ & $\begin{array}{c}\text { anion }^{\mathrm{b}} \\
\left(\log \in_{\max }\right)\end{array}$ & $\lambda^{\mathrm{c}} \mathrm{nm}$ & $\mathrm{H}^{1 / 2 \mathrm{~d}}$ & corr. $^{\mathrm{e}}$ \\
\hline 1 & $264(3.21)$ & $262(3.35)$ & 258 & 9.78 & 0.99 \\
2 & $259(3.33)$ & $265(3.12)$ & 258 & 8.40 & 0.99 \\
3 & $262(3.37)$ & $264(3.34)$ & 262 & 9.44 & 0.99 \\
4 & $258(3.82)$ & $265(4.00)$ & 265 & 8.37 & 0.99 \\
5 & $269(3.74)$ & $271(3.80)$ & 243 & 12.43 & 0.99 \\
6 & $271(3.71)$ & $275(3.76)$ & 292 & 12.26 & 0.99 \\
7 & $271(3.74)$ & $272(3.70)$ & 294 & 11.36 & 0.99 \\
8 & $271(3.65)$ & $273(3.79)$ & 294 & 12.45 & 0.99 \\
\hline
\end{tabular}

${ }^{a}$ Measured in $\mathrm{pH}=7$ buffer solution. ${ }^{\mathrm{b}}$ Measured in $\mathrm{pH}=13$ buffer solution. ${ }^{\mathrm{c}}$ The analitical wavelength for $p \mathrm{~K}_{\mathrm{a}}$ determination. ${ }^{\mathrm{d}}$ Half-protonation values. ${ }^{e}$ Correlations for $\log I$ as a function of $\mathrm{pH}$ graph.

Table 3. The UV Spectral data and the acidity constants, $\mathrm{pK}_{\mathrm{a} 2}$ values, of compounds 1-8 for the first protonation process

\begin{tabular}{cccccc}
\hline & \multicolumn{2}{c}{ spectral maximum $\lambda / \mathrm{nm}^{\mathrm{a}}$} & \multicolumn{3}{c}{ acidity measurements } \\
\cline { 2 - 6 } compound & $\begin{array}{c}\text { neutral }^{\mathrm{a}} \text { species } \\
\left(\log \in_{\max }\right)\end{array}$ & $\begin{array}{c}\text { monocation }^{\mathrm{b}} \\
\left(\log \in_{\max }\right)\end{array}$ & $\lambda^{\mathrm{c} n m}$ & $\mathrm{H}^{1 / 2 \mathrm{~d}}$ & corr. $^{\mathrm{e}}$ \\
\hline 1 & $264(3.21)$ & $255(3.45)$ & 286 & 4.57 & 0.99 \\
2 & $259(3.33)$ & $257(3.28)$ & 258 & 3.80 & 0.99 \\
3 & $262(3.37)$ & $259(3.41)$ & 290 & 3.84 & 0.99 \\
4 & $258(3.82)$ & $257(4.02)$ & 293 & 4.45 & 0.99 \\
5 & $269(3.74)$ & $263(3.68)$ & 243 & 3.94 & 0.99 \\
6 & $271(3.71)$ & $267(3.67)$ & 292 & 3.02 & 0.99 \\
7 & $271(3.74)$ & $266(3.61)$ & 294 & 3.50 & 0.99 \\
8 & $271(3.65)$ & $272(3.59)$ & 294 & 3.65 & 0.99 \\
\hline
\end{tabular}


${ }^{\mathrm{a}}$ Measured in $\mathrm{pH}=7$ buffer solution. ${ }^{\mathrm{b}}$ Measured in $\mathrm{pH}=1$ buffer solution. ${ }^{\mathrm{c}}$ The analytical wavelength for $p \mathrm{~K}_{\mathrm{a}}$ determination. ${ }^{\mathrm{d}}$ Half-protonation value. ${ }^{\mathrm{e}}$ Correlation for $\log \mathrm{I}$ as a function of $\mathrm{pH}$ graph.

Table 4. The UV Spectral data and acidity constants, $\mathrm{pK}_{\mathrm{a} 3}$ values, of compounds 1-4 for the second protonation

\begin{tabular}{|c|c|c|c|c|c|c|c|}
\hline \multirow[b]{2}{*}{$\begin{array}{c}\text { compoun } \\
\mathrm{d}\end{array}$} & \multicolumn{2}{|c|}{ spectral maximum $\lambda / \mathrm{nm}$} & \multicolumn{5}{|c|}{ acidity measurements } \\
\hline & $\begin{array}{c}\text { mono cation }^{\mathrm{a}} \\
\left(\log \in_{\max }\right)\end{array}$ & $\begin{array}{l}\text { dication }^{\mathrm{b}} \\
(\log \in \max )\end{array}$ & $\lambda^{c} \mathrm{~nm}$ & $\mathrm{H}^{1 / 2 \mathrm{~d}}$ & $\mathrm{~m}^{\mathrm{e}}$ & $\mathrm{pK}_{\mathrm{a} 1}^{\mathrm{f}}$ & corr. $^{g}$ \\
\hline 1 & $255(3.45)$ & $256(3.32)$ & 284 & 1.30 & 0.57 & 0.74 & 0.90 \\
\hline 2 & $257(3.28)$ & $258(3.34)$ & 265 & 2.18 & 1.02 & 2.18 & 0.98 \\
\hline 3 & $259(3.41)$ & $258(3.44)$ & 267 & 1.86 & 0.17 & 0.31 & 0.93 \\
\hline 4 & $257(4.02)$ & $258(3.33)$ & 293 & 3.10 & 0.20 & 0.62 & 0.99 \\
\hline
\end{tabular}

${ }^{a}$ Measured in $\mathrm{pH}=1$ buffer solution. ${ }^{\mathrm{b}}$ Measured in $\% 50 \mathrm{H}_{2} \mathrm{SO}_{4} \cdot{ }^{\mathrm{c}}$ The analytical wavelength for $p \mathrm{~K}_{\mathrm{a}}$ determination. ${ }^{\mathrm{d}}$ Half-protonation value. ${ }^{\mathrm{e}}$ Slopes for $\log \mathrm{I}$ as a function of $\mathrm{pH}$ (or acidity function $H_{\mathrm{o}}$ ) graph. ${ }^{27} \mathrm{f}$ Acidity constant value ${ }^{g}$ Correlation for $\log \mathrm{I}$ as a function of $\mathrm{H}_{\mathrm{o}}$ graph.

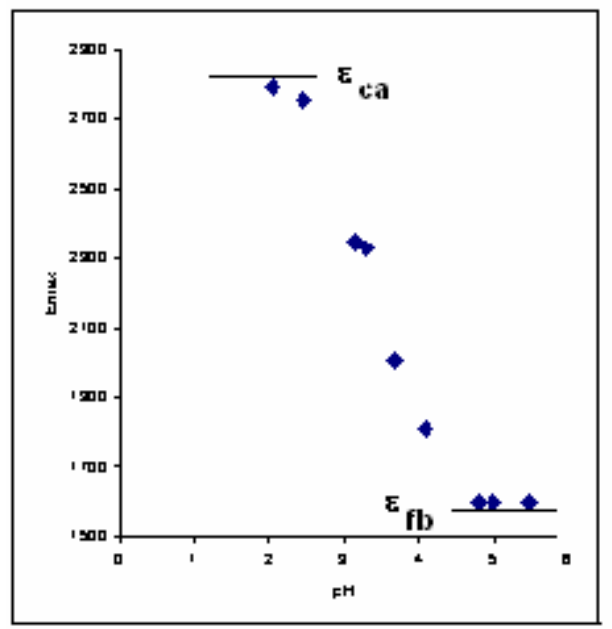

Figure 1. $\in_{\max }$ as a function of $\mathrm{pH}($ at $294 \mathrm{~nm}$ ) for plot for the first protonation of 2-\{[(6-methylbenzothiazol-2-yl)amino $]$ methyl $\}$ phenol molecule 7. 


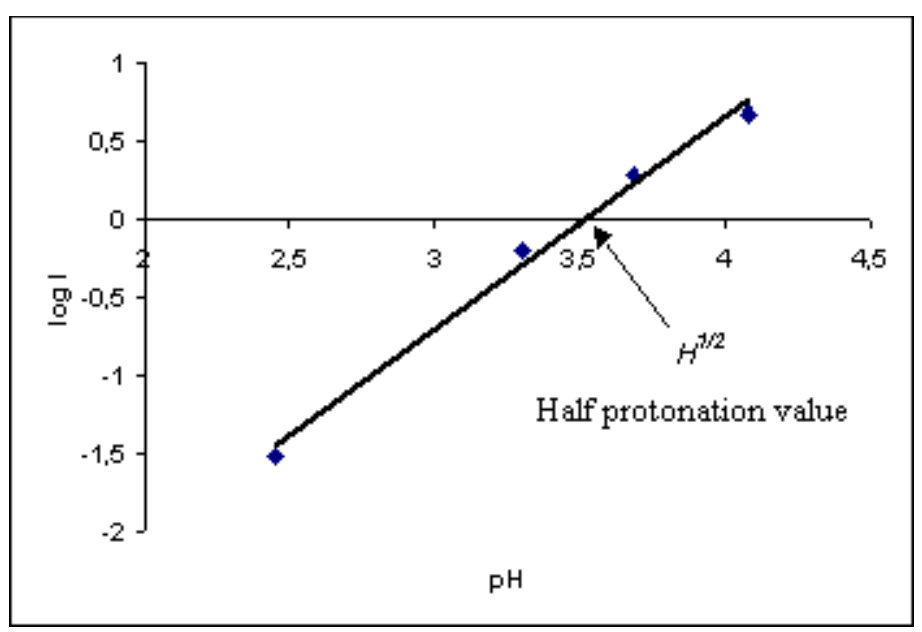

Figure 2. $\mathrm{pH}$ as a function of $\log I$ (at $294 \mathrm{~nm}$ ) plot the first protonation of 2-\{[(6- methylbenzothiazol-2-yl) amino $]$ methyl $\}$ phenol molecule 7.

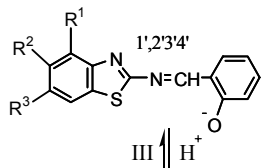

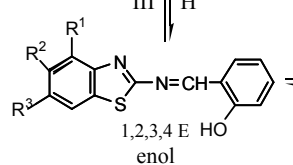<smiles></smiles>

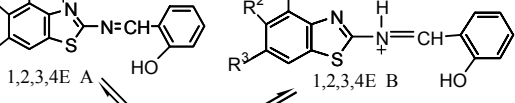
$\mathrm{IV} \mathrm{K}_{3}$

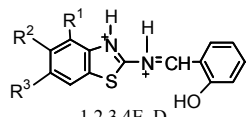

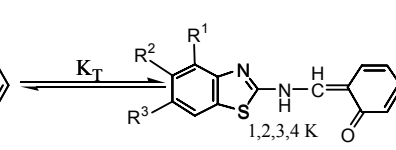

keto

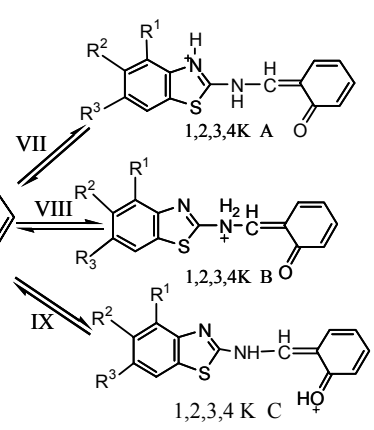

$1 \mathrm{E}^{1,2,3}=\mathrm{H}$
$2 \mathrm{E}^{1}=\mathrm{CH}_{3}, \mathrm{R}^{2,3}=\mathrm{H}$
$3 \mathrm{E}^{1,2}=\mathrm{H}, \mathrm{R}^{3}=\mathrm{CH}_{3}$
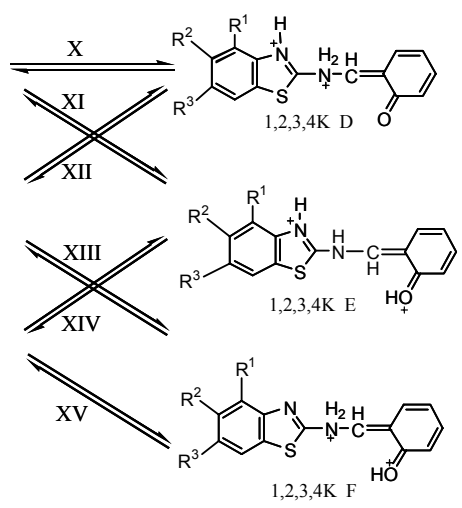

Scheme 6. Possible deprotonation, first and the second protonation pathways for the enol and keto forms of studied benzothiazole Schiff bases $[\mathbf{1}-\mathbf{4}]$. 


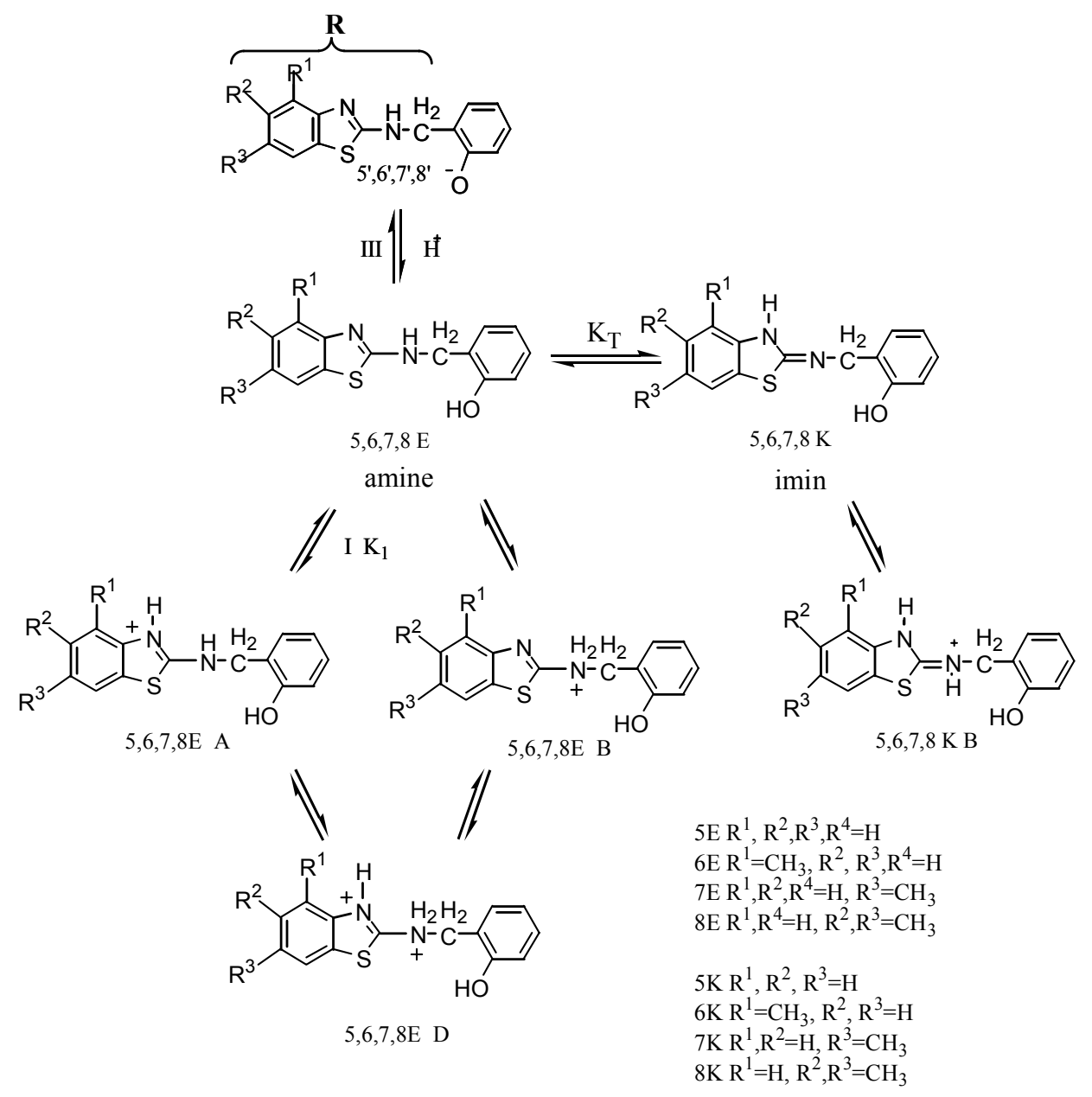

Scheme 7. Possible deprotonation, the first protonation and the second protonation pathways for the amine and imin forms of the studied reduced benzothiazole Schiff bases $[5-8]$.

\section{Acknowledgements}

We thank to Eskişehir Osmangazi University, The Presidency of the Commission of Scientific Research Projects for financial support this work via research project number of 200419032.

\section{References}

1. Cohen, M. D.; Schmidt, G. M. J.; Flavian, S. J. Chem. Soc. 1964, 2041.

2. Hadjoudis, E.; Vittorakis, M.; Moustakali, I.; Mavridis, I. Mol. Cryst. Liq. Cryst. 1986, 1, 137.

3. Dash, B.; Patra, M.; Praharaj, S. Ind. J. Chem. 1980,19B, 894. 
4. Scozzafava, A.; Briganti, F.; Ilies, M. A.; Supuran, C. T. J. Med. Chem. 2000, 43, 292.

5. Duta, R. L.; Hossain, M. M. J. Sci. Ind. Res. 1985, 44, 635.

6. Williams, D. R.; The Metals of Life, Van Nostrand: London, 1971.

7. Sigel, H.; McCormick, D. B. Acct. Chem. Res. 1970, 3201.

8. Dixon, M.; Webb, E. C.; Enzymes, Green and Co: London, 1964.

9. Williams, D. R. Chem. Rev. 1972, 72, 203.

10. Albert, A. Aust. J. Sci. 1967, 30, 177.

11. Kirschner, S.; Wei, Y. K.; Francis, D.; Bergman, J. U. J. Med. Chem. 1966, 9, 369.

12. Crim, J. A.; Buskirk, H. H.; Petering, H. G. Cancer. Res. 1967, 27, 1109.

13. Scozzafava, A.; Mastrolorenzo, A.; Supuran, C. T. Exp. Opin. Ther. Patents. 2001, 11, 765.

14. Huang, M.; Maynard, A.; Turpin, J. A.; Lisa, G.; Janini, G. M.; Covell, D. G.; Rice, W. G. J. Med. Chem. 1998, 41, 1371.

15. Heim, M. E.; Metal Complexes in Chemotherapy; 4th Edn.; Verlag Chemie: Weinheim, 1993.

16. Brown, H. C.; McDaniel, O. H.; Haflinger, O. Determination of Organic Structure by Physical Methods; Academic Press: New York, 1985.

17. Chilton, J.; Stenlake. J. B. J. Pharm. Pharmacol. 1962, 14, 367.

18. Johnson, C. D. The Hammett Equation; Cambridge University Press: Cambridge, 1973.

19. Frey, P. A.; Kokesh. F. O.; Wcstheimer, F. H. J. Am. Chem. Soc. 1971, 93, 7266.

20. $\mathrm{PhD}$ Thesis of Kamuran Görgün, Eskişehir Osmangazi University, 2008, Eskişehir, Turkey.

21. Cookson, R. F. The determination of acidity constants, Chem. Rev. 1974, 74, 1.

22. Perrin, D. D. Dissociation constants of organic bases in aqueous solution, Butterworths: London., 1972.

23. Perrin, D. D.; Dempsey, B.; Sergeant, E. P. pK $K_{a}$ Prediction for Organic Acids and Bases, Chapman and Hall: London., 1981.

24. Katritzky, A. R. Physical Method of Heterocyclic Chemistry; Academic Press: New York, 1963.

25. Bowden, K. Chem. Rev. 1966, 66, 2.

26. Perrin, D. D. Buffers for pH and Metal Ion Control; Chapman and Hall: London, U.K., 1971.

27. Albert, A.; Serjeant, E. P. The Determination of Ionisation Constants; Chapman and Hall: London, U.K., 1971.

28. Deno, N. C.; Jaruzelski, J. J. J. Am. Chem. Soc. 1955, 77, 3044.

29. Orloft, M. K.; Fitts, D. D. J. Chem. Phys. 1963, 38, 2334.

30. Yates, K.; Stevens, J. B.; Katritzky, A. R. Can. J. Chem. 1964, 42, 1957.

31. Schawarzenbach, G.; Sulzberger, R. Helv. Chim. Acta 1944, 27, 348.

32. Yates, K.; McClelland. R. A. J. Am. Chem. Soc. 1967, 89, 2686. 